\title{
SOFTWARE CO-DEVELOPMENT BETWEEN SUPPLIER AND BUYER - BENEFITS, RISKS AND ENABLERS
}

\author{
Antti Rantala,VTT, antti.rantala@vtt.fi \\ Josu Takala, University of Vaasa, josu.takala@uwasa.fi \\ Helena Kortelainen, VTT, helena.kortelainen@vtt.fi
}

\begin{abstract}
Digitalization changes many industries since manufacturers are increasing the automation level in their products. Novel business needs require developed softwares, and that often leads companies to seek external skills for software development either by hiring more software engineers or by purchasing tailored softwares from software companies. However, prices in the software industry can be high, and hiring new software engineers or purchasing tailored softwares may become expensive. Co-developing software with other companies could be a convenient method for sharing the costs and risk in software development. As a result of this literature review study, different co-development models - such as contractual alliances and joint ventures - are proposed as potential governance models for software co-development. In addition, an interview template for evaluating other companies' willingness for interorganizational software development was developed.
\end{abstract}

Keywords: Collaboration, Software, Joint Venture, Contractual alliance

\section{INTRODUCTION}

As companies are increasing automation level in their products, complex softwares and systems are needed. Machine manufacturers rarely have sufficient software skills in-house which often leads them to hire more software engineers or to purchase tailored softwares from software companies. However, prices in the software industry can be relatively high and their delivery capacity limited and hiring new software engineers or purchasing tailored softwares may not be the most cost-effective way to get the softwares into the products.

This paper investigates the possibility of co-developing softwares with suppliers instead of hiring new software engineers or acquiring tailored softwares. Co-development could be convenient way to share risks and costs of large software development projects. However, when co-developing knowledge-intensive products, it is important to take care of jointly created value and intellectual property rights (IPR). For this reason, there has to be precisely determined contracts about how to share costs and results of the collaboration.

This paper suggests that the software co-development could take place in a contractual alliance or in a joint venture. In a contractual alliance, contracts are made to define the playing rules of the collaboration and to agree beforehand on the value sharing between the companies. In a joint venture, two companies form a separate legal entity in which the co-development takes place. In this model, costs and revenues are shared according to the shareholding agreements.

\section{BACKGROUND AND LITERATURE REVIEW}

For many years, vendors have been practicing software development in a relative isolation from other companies. However, at some point they started to open the software products towards co-development and started to realize the benefits of collaboration. Large-scale software products (e.g. operating systems) started to transform from singlevendor projects into co-development projects and software ecosystems (Kourtesis, Bratanis, Bibikas \& Paraskakis, 2012). Companies are shifting from traditional contracting to co-development and common projects, and the strategic objectives of business cooperation are becoming deeper than in traditional supplier-buyer relationships. Keil, Maula, Schildt, \& Zahra (2008) found in their study that joint ventures among ICT companies have improved their innovative 
performance. An agile company that has the ability to react quickly to the market changes can exploit networking with other companies to achieve its goals. In a successful collaboration, all parties benefit from the results. Collaboration has long been the norm for knowledge-intensive business services (KIBS) firms, which rely heavily on technical or professional knowledge to help their clients to overcome their problems (Miozzo, Desyllas, Lee \& Miles, 2016).

Formality of the inter-organizational collaboration can vary from personal links to different kinds of corporate arrangements. The contracts between companies define the depth and formality of the business collaboration. However, collaboration should not be formed only based on contracts, because collaboration should always be developed based on operations and actions among people. Contracts and corporate arrangements should be seen only as a tool for protecting own business. Figure 1 presents different formality levels of business collaboration (Vesalainen 1996).

\begin{tabular}{|c|c|c|}
\hline $\begin{array}{l}\text { Personal and/or unofficial } \\
\text { links }\end{array}$ & $\begin{array}{l}\text { Links based on written } \\
\text { contracts }\end{array}$ & $\begin{array}{l}\text { Cross ownership and } \\
\text { joint venture }\end{array}$ \\
\hline $\begin{array}{l}\text { Links based on oral } \\
\text { agreements }\end{array}$ & & ture \\
\hline
\end{tabular}

Figure 1 Intensity Levels of Inter-organizational Collaboration (Vesalainen 1996)

Saarnilehto et al. (2013) argue that business relationships among organizations can be categorized in two extremes: market-based relationships and collaboration relationships. In market-based relationships, the products and services that companies exchange are standardized and simple. The relationship is mainly based on the price of the product and the companies do not have a deep strategical linkage between each other.

In collaboration relationships, the exchange between companies may be complicated. They may exchange complex systems or necessary components between each other, and the supplier may be a part of the customer's product development. There might be a lot of tailoring in the exchanged products and services. The mutual dependency between the companies may be significant, and the strategic linkage between the companies might be extremely strong. The development and maintenance of the relationship is essential, because replacing the partner would be expensive or even impossible. The partners may have common objectives and contractual agreements for sharing their jointly created value. The structural linkages can be deep, and there may be many interfaces between the companies. The social structures are essential, since collaboration relationships require high level of trust. Dialogical communication is essential for developing the trust and solving major problems together (Saarnilehto et al. 2013).

\section{Inter-organizational product development}

Inter-organizational collaboration has increased in recent years, as even large OEMs (Original Equipment Manufacturers) do not possess all the necessary expertise and skills in-house for developing complex products where a wide range of expertise and different forms of expertise are required. As big OEMs are developing complex products, small specialist companies are becoming more directly involved in product development processes (van der Meer Kooistra \& Scapens, 2015). Sometimes, the OEM branded end products are almost entirely produced by external partners. Suppliers' role has grown in recent years, since they may be needed also in the product development process. The increasing technological complexity have weakened individual companies' changes to develop their products without external expertise. By combining the expertise of different component or system providers, companies can grow the availability of special skills and technology in their product development processes. Collaboration that aims to develop new technological solutions, service concepts, products, or business models, requires specific contracts to ensure fair sharing of risks and potential benefits (Saarnilehto et al., 2013). 


\section{Benefits of inter-organizational product development}

Organizations that engage in collaborative R\&D efforts have the opportunity to combine their complementary expertise by facilitating the generation of technological inventions that organizations could not achieve on their own (Belderbos, Cassiman, Faems, Leten \& Van Looy 2014). Keil et al. (2008) found that the increased use of more open governance forms, such as alliances and joint ventures, leads to increased innovation outcomes for companies. Interorganizational product development between suppliers and customers has led into improved quality of products, quicker product development processes, and improved suitability for customers' needs and decreased product development costs (Saarnilehto et al., 2013). By bringing more partners into the software development process, customer needs can be satisfied with less capital investments. In addition, collaboration in software development generate further advantages, such as decreased software and business development costs and increased speed in development processes (Kourtesis, Bratanis, Bibikas \& Paraskakis, 2012).

\section{Risks in inter-organizational product development}

Creating a business model that involves co-development of core elements of a company's product or service offering can be extremely risky (Chesbrough \& Schwartz, 2007). Because collaboration requires the combined effort of partners, they cause coordination complexities, which may lead into conflicts and frustrations. Collaboration may also cause financial risks and organizational risks such as the risk of becoming overly dependent of the partner. In addition, deep collaboration may result in a loss of decision-making control in some functions (Tjemkes et al., 2012). Sharing information within a network causes uncertainty and risk, and it is unclear how to reach the sufficient level of trust between partners in order to make them feel comfortable to be open (Tsou et al., 2018). Continuous exchange of knowledge with partners can expose companies to conflicts concerning the ownership of co-developed products together with the knowledge leakages that both are regarded as considerable risks in a deep collaboration (Miozzo et al., 2016). Proprietary information can be lost to a company who is a competitor or eventually will become one (Tjemkes et al., 2012).

In the co-development projects, conflicts over ownership of the co-developed knowledge assets is a common problem. The service provider may want to replicate the solution with other clients, whereas the client might want to use it in its own activities and may want to prevent it from being offered to other companies (Miozzo et al. 2016). For example, SW provider could sell their co-developed solutions to the firms that are in direct competition with their customers, if it is not restricted in the contracts.

\section{Enablers for inter-organizational product development}

Sufficient inter-organizational control is essential for collaborative product development, since it governs the partners' behavior, increases mutual resource sharing and reduces the expenses of collaboration. Contract control establish and maintain collaborative relationships through series of laws, agreements and management procedures. Contracts provide clear, legal, and institutional rules to define the responsibilities of partners. Contracts may also include penalty rules to prevent opportunistic behavior. Precisely made contracts help to create an atmosphere that supports open communication and knowledge sharing. Consequently, a proper contract control provides clear institutional rules and fair solutions for problems, which reduces conflicts among partners and increases collaboration satisfaction ( $\mathrm{Lu}$, Yan $\& \mathrm{Wu}, 2017)$.

Formal appropriability mechanisms may facilitate a favorable environment for product co-development by providing a framework for what knowledge is shared, and what remains private (Miozzo et al., 2016). Appropriability refers to capacity of the firm to retain the value it creates for its own benefit and common mechanisms are for example patents, licensing contracts, trademarks and secrecy. The existence and use of legal appropriability methods may give managers the confidence to interact more widely with other firms. Moderate emphasis on formal appropriability mechanisms can prevent conflicts over ownership of jointly developed assets and knowledge leakages (Miozzo et al., 2016). However, overly strict control may have negative effects, because they may prevent companies to be open for cooperation (Laursen \& Salter, 2014). In order to gain the mutual benefits from the inter-organizational collaboration, the relations and contracts among the parties has to be managed precisely and effectively (Saarnilehto, 2013). Research studies underline the importance of complex contracts in knowledge-intensive service industry in collaborative product development. They may facilitate knowledge transfer and prevent conflicts over jointly developed knowledge assets (Miozzo et al., 2016). Another essential element in collaboration is joint decision making that refers to as the 


\section{Issues in Information Systems}

Volume 21, Issue 1, pp. 91-97, 2020

extent to which collaborating companies jointly take crucial decisions. Without decision synchronization, participating companies are likely to suffer from financial and nonfinancial losses (Um \& Kim, 2018).

\section{RESEARCH METHOD}

Comprehensive literature review was carried out in order to create visual illustrations for different business models that could enable inter-organizational software development. The literature study gave also the necessary background in order to create an interview template for measuring companies' willingness for inter-organizational software development and to identify which benefits, risks and enablers they perceive as the most essential in such collaboration.

\section{RESULTS}

Based on the literature study, three different models for SW acquisition were developed. The models include the traditional software purchasing, contractual alliance and joint venture. Traditional software purchasing is a common method to acquire the necessary software into machinery delivery. In this model, the machinery manufacturer sets the requirements for the software, and software company creates a software that fulfills the stated requirements. Manufacturer buys the software and becomes the IPR owner of the purchased software. Software can also be licensed and in this case, the ownership rights remain in the software company, but the manufacturer company get the user rights for the software. Figure 2 presents the traditional software-purchasing model that is widely used in manufacturing industries.

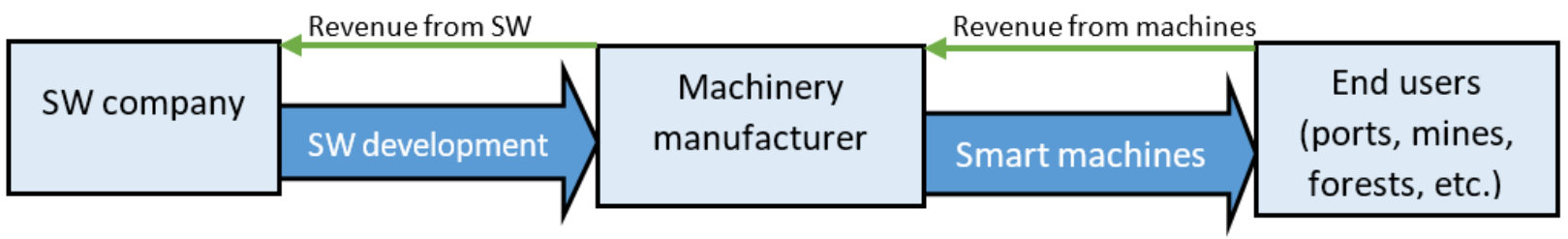

Figure 2. Traditional Software Purchasing

When two or more companies are horizontally integrated, they form an alliance. An alliance is a contractual relationship between two or more independent organizations, designed to achieve mutual and individual objectives (Tjemkes, Burges \& Vos, 2012). Contractual alliance could be a potential governance model for inter-organizational software development. Figure 3 demonstrates how software development could take place in a contractual alliance.

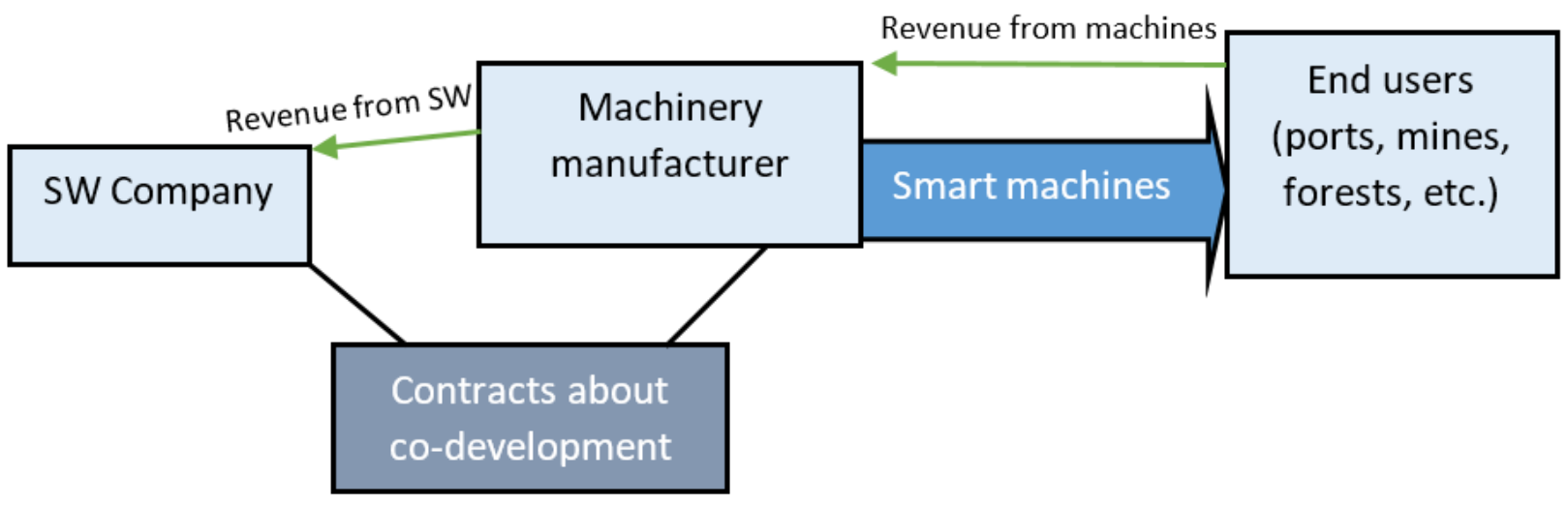

Figure 3. Software Co-development in Contractual Alliance

Contractual alliance is established by contractual agreements that can be very complex and detailed. In a contractual alliance, companies complement each other's expertise and resources, which leads into productive synergy effects. In 
the contractual alliance, companies have their alliance teams working together. Alliance contracts define responsibilities and ensure fair cost and value sharing. The contracts may also include arrangements regarding shared IPR of co-created softwares. Alliance model represents strategically deeper collaboration model than traditional software purchasing.

Software co-development can take place also in a joint venture. A joint venture is a separate legal entity that is established for joint software development. Figure 4 demonstrates how creating a joint venture could enable interorganizational software development.

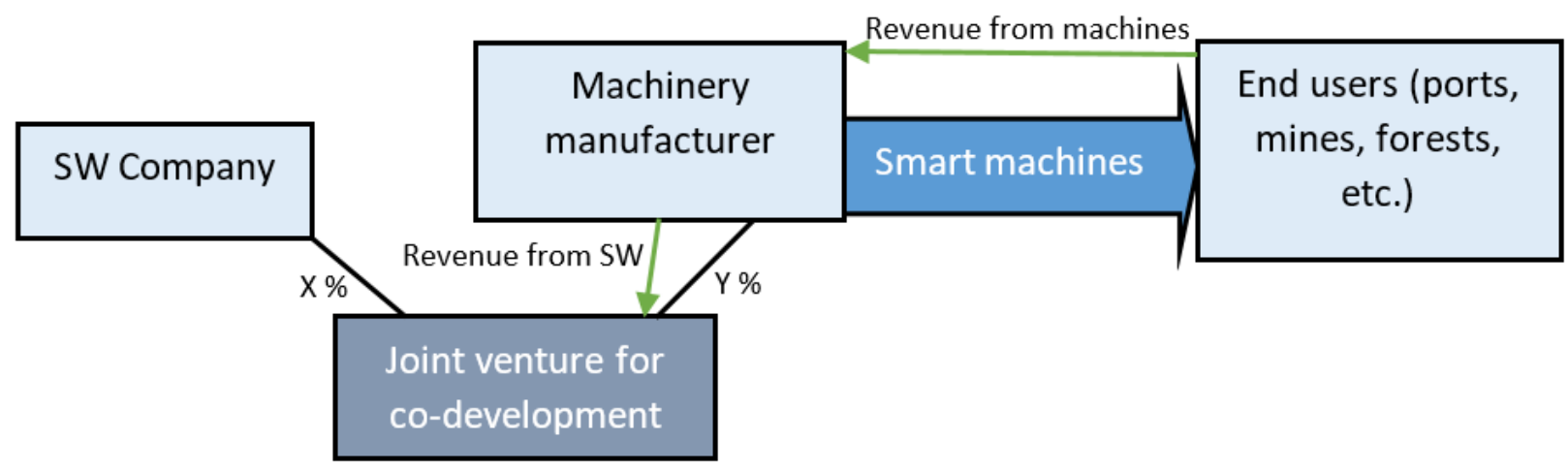

Figure 4. Software Co-development in Joint Venture

In a joint venture, partners own a certain share of the joint venture company, and the cost and revenues are divided according to the shareholding agreements. The incorporation of the collaboration, i.e. setting up a novel company together, may be important, because the joint development may generate innovations with great business potential, and owning the IPR of the jointly generated products might be extremely valuable.

The literature study gave the necessary background for an interview template that could be applied when measuring companies' willingness for inter-organizational software development and to identify which benefits, risks and enablers they perceive as the most essential regarding such collaboration. First, the possible governance models for co-development were identified, so the interviewee can express his or her interest towards those models. Then, the main benefits, risks and enablers regarding deep collaboration were listed so that the interviewee can express his or her opinions regarding them. The purpose of the template is to examine manufacturing companies' willingness for inter-organizational software development with software companies. If the manufacturer and software company get interested of joint software development, they can start negotiating about the terms and contracts of possible collaboration.

The template in Table 1 can be used as a checklist when examining other companies' interests and opinions regarding the inter-organizational software development. The interviewee should answer to each section by a number from one to five. It is also possible to ask explanations for each answer in order to get depth into the interview. In the beginning of the interview, it is recommendable to introduce the figures that visualize traditional purchasing, contractual alliance and joint venture business models to the interviewee. The visual illustrations of different business models will help the interviewee to get better understanding of the subject. 
Table 1. Template for Examining Companies' Interest towards Inter-organizational Software Development Evaluate each section by number from one to five

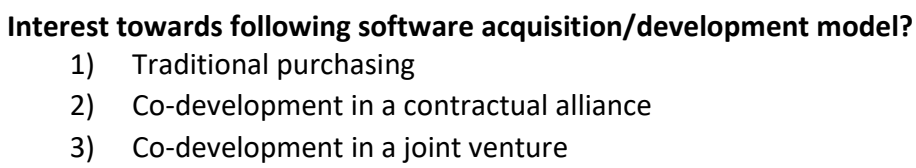

1) Risk of opportunistic behavior by partner

2) Risk of losing trade secret to others

3) Risk of unfair sharing of jointly created value

4) Risk of getting too dependent of the partner

5) Other benefits, which?

How essential are following enablers concerning your willingness towards deep inter-organizational software development?

1) Trust among companies

2) Precisely determined contracts

3) Open knowledge sharing among companies

4) Complementarity of the companies

5) Other enablers, which?

\begin{abstract}
SUMMARY
Large software development projects are expensive, and they require a lot of workforce and recourses. Co-developing software with other companies could be a potential method for sharing the costs and risks in large software projects. Inter-organizational product development may bring benefits such as increased creativity, reduced time to market and reduced development costs. However, there are always risks in deep collaboration, for example risk of becoming too dependent of the partner, risk unfair revenue sharing and risk of opportunistic behavior by a partner. Enablers for deep collaboration are for example trust, sufficient contract making skills and open knowledge sharing among the companies.

This paper proposes beyond traditional purchasing two governance models that could enable inter-organizational software development. The first model is a contractual alliance, in which contracts define responsibilities and cash flows between the companies. The other model is forming a joint venture for software development. In that model, the shareholding agreements define the cost and revenue streams. In addition, an interview template is provided that can be used when examining other companies' willingness for inter-organizational software development.
\end{abstract}

\title{
AKNOWLEDGMENTS
}

This paper is conducted as a part of VTT Technical Research Centre of Finland's AUTOPORT project. AUTOPORT - Operational excellence and novel business concepts for autonomous logistic systems in ports - is a co-innovation project consortium which objective is to pave the way towards business renewal and operational excellence by developing ecosystem level approaches for logistic robot systems. This paper is based on A. Rantala's Master's Thesis "Inter-organizational collaboration in software product development". 


\section{Issues in Information Systems}

Volume 21, Issue 1, pp. 91-97, 2020

\section{REFERENCES}

Belderbos, R., Cassiman, B., Faems, D., Leten, B. \& Van Looy, B. (2014) Co-ownership of property - Exploring the value appropriation and value creation implications of co-patenting with different partners. Research policy, 43(5), 841-852. https://doi.org/10.1016/j.respol.2013.08.013

Chesbrough, H. \& Schwartz, K. (2007) Innovating business models with co-development partnerships. Research Technology Management, 50(1), 55-59. Retrieved 19-09-2019 from https://search.proquest.com/technology1/docview/213800966?accountid=27306\&pq-origsite=summon

Keil, T., Maula, M., Schildt, H. \& Zahra, S.A., (2008) The effect of governance modes and relatedness of external business development activities on innovative performance. Strategic Management Journal, 29(8), 895-907. https://doi.org/10.1002/smj.672

Kourtesis, D., Bratanis, K., Bibikas, D. \& Paraskakis, I. (2012) Software Co-Development in the Era of Cloud Application Platforms and Ecosystems: The Case of CAST. Collaborative Networks in the Internet of Services (p. 196-204) Springer, Berlin, Heidelberg.

Laursen, K. \& Salter, A. (2014) The paradox of openness: Appropriability, external search and collaboration. Research Policy, 43(5), 867-878. https://doi.org/10.1016/j.respol.2013.10.004

Lu, P., Yan, S. \& Wu, J. (2017) The interaction effect between intra-organizational and inter-organizational control on the project performance of new product development in open innovation. International Journal of Project Management, 35(8), 1627-1638. https://doi.org/10.1016/j.ijproman.2017.09.009

Miozzo, M., Desyllas, P., Lee, H. \& Miles, I. (2016) Innovation collaboration and appropriability by knowledgeintensive business. Research Policy. 45(7), 1337-1351. https://doi.org/10.1016/j.respol.2016.03.018

Saarnilehto, V., Vesalainen, J. \& Annola, V. (2013). Monimuotoinen verkosto - johtamista ja juridiikkaa. Helsinki: Kauppakamari (in Finnish)

Tjemkes, B., Burgers, K. \& Vos, P. (2012) Strategic alliance management. New York: Taylor \& Francis Group

Tsou, H., Chen, J. \& Yu, Y. (2018) Antecedents of co-development and its effect on innovation performance: A business ecosystem perspective. Management Decision, 57(7), 1609-1637. Available: www.emeraldinsight.com/0025-1747.htm

Um, K. \& Kim, S. (2018) Collaboration and opportunism as mediators of the relationship between NPD project uncertainty and NPD project performance. Internal Journal of Project Management, 36(4), 659-672. https://doi.org/10.1016/j.ijproman.2018.01.006

van der Meer-Kooistra, J. \& Scapens, R. (2015) Governing product co-development projects: the role of minimal structures. Management Accounting Research, 28, 68-91. https://doi.org/10.1016/j.mar.2015.05.001

Vesalainen, J. (1996). Yritysyhteistyön malleja - käsikirja yhteistyön edistäjille. Helsinki: Edita.

Yan, T. \& Wagner, S. (2017) Do what and with whom? Value creation and appropriation in inter-organizational new product development projects. International Journal of Production Economics, 191 September, 1-14 https://doi.org/10.1016/j.ijpe.2017.05.010 